\title{
Aortic size index enlargement is associated with central hemodynamics in essential hypertension
}

\author{
Alberto Milan ${ }^{1}$, Francesco Tosello ${ }^{1}$, Mimma Caserta ${ }^{1}$, Diego Naso ${ }^{1}$, Elisabetta Puglisi ${ }^{1}$, Corrado Magnino ${ }^{1}$, \\ Chiara Comoglio $^{2}$, Franco Rabbia ${ }^{1}$, Paolo Mulatero ${ }^{1}$ and Franco Veglio ${ }^{1}$
}

The aim of this study was to evaluate the association between brachial and central blood pressure (bBP and cBP) levels and aortic root dilatation (ARD) in essential hypertensive patients. A total of 190 untreated and treated essential hypertensive patients (mean age, $55 \pm 11$ years) were considered for this analysis. We measured pulsatile hemodynamics and the proximal aortic diameter directly using tonometry, ultrasound imaging (echocardiography) and Doppler. Ninety-one hypertensive patients had an ARD (defined as aortic size index $(\mathrm{ASi})>2 \mathrm{~cm} / \mathrm{m}^{2}$ ). Central hemodynamic variables were significantly associated with ASi. Patients with increased ASi were significantly older $(60 \pm 10$ vs. $50 \pm 11$ years, $P<0.0001)$ and had higher levels of the augmentation index (Alx; $28 \pm 10$ vs. $21 \pm 10 P<0.0001$ ), augmentation pressure (AP; $13 \pm 6$ vs. $8 \pm 5 \mathrm{~mm} \mathrm{Hg}, P<0.0001$ ), and central pulse pressure (cPP; $44 \pm 10$ vs. $39 \pm 8 \mathrm{~mm} \mathrm{Hg}, P<0.0001$ ) compared with patients with normal ASi. In a logistic regression analysis, the Alx was the only significant predictor of $A S i$. In hypertensive patients, the Alx and cBP were associated with ARD, whereas the bBP was not. Patients with an increased ASi may lose part of the elastic properties of the aorta, demonstrating a strict correlation between ASi and central hemodynamic indexes, in particular, the CPP and Alx. Hypertension Research (2011) 34, 126-132; doi:10.1038/hr.2010.185; published online 30 September 2010

Keywords: aortic root dilatation; aortic stiffness; central blood pressure

\section{INTRODUCTION}

Elevated blood pressure (BP) is a leading cause of aortic root dilatation (ARD) in people with hypertension and those genetically pre-disposed to $A R D$, that is, those with bicuspid aortic valve disease or Marfan's disease. ${ }^{1}$ The wall tension, given by the product of the circumferential stress and wall thickness, is directly proportional to BP and the vessel diameter, thus explaining why both hypertension and aortic dilation are risk factors for aortic dissection. ${ }^{1}$ Nevertheless, brachial blood pressure (bBP) levels are only weakly associated with aortic diameter. ${ }^{2}$ Recent studies have suggested that central aortic BP may be better associated with target organ damage and clinical outcomes in people with hypertension. ${ }^{3-7}$ Moreover, in Marfan's disease, it has been previously shown that central blood pressure (cBP) has a key role in the pathogenesis of aortic aneurysms. ${ }^{8}$ In hypertensive patients, the $\mathrm{ARD}$, and in particular dilatation of the sinus of Valsalva, is associated with more pronounced alterations in cardiac structure and geometry than in normotensive subjects; ${ }^{2}$ however, the relationship between aortic root size and both the central and the peripheral BP levels has not yet been fully investigated in patients with hypertension and aortic dilatation.

The aim of our study was to evaluate the association between $\mathrm{bBP}$ and $\mathrm{cBP}$ levels and the diameter of the proximal aorta in essential hypertensive patients, both with normal and with dilated aortic roots.

\section{METHODS}

We evaluated 190 adult outpatients with essential hypertension who were referred consecutively to the echo lab of the Hypertension Unit at the University of Turin, Italy for evaluation of target organ damage.

For the recruitment, all individuals underwent a full medical examination. All BP measurements were performed according to the European Society of Hypertension/European Society of Cardiology ${ }^{9}$ recommendations. Hypertension was defined by systolic blood pressure (SBP) $\geqslant 140$ and/or diastolic blood pressure (DBP) $\geqslant 90$ on three consecutive occasions or by the assumption of the use of antihypertensive medications.

The exclusion criteria were the following: age $<18$ years or $>70$ years, $\mathrm{BMI} \geqslant 40$, secondary hypertension, non-hypertensive cardiovascular disease, any valvulopathy more than mild, a bicuspid aortic valve, diabetes, the presence of associated clinical conditions as defined by the European Society of Hypertension/European Society of Cardiology ${ }^{9}$ guidelines, a family history of aortic rupture, or clinical characteristics suggesting a genetic pre-disposition to ARD such as Marfan's syndrome. The study was approved by our Institutional Review Committee and all subjects provided their written informed consent.

1Department of Medicine and Experimental Oncology, Division of Internal Medicine, Hypertension Unit, University Hospital 'S. Giovanni Battista', Torino, Italy and '2Division of Cardiovascular Surgery, University Hospital 'S. Giovanni Battista', Turin, Italy

Correspondence: Dr A Milan, Department of Medicine and Experimental Oncology, Division of Internal Medicine, Hypertension Unit, University Hospital ‘S. Giovanni Battista', Via Genova, 3 Torino 10126, Italy.

E-mail: alberto.milan@unito.it

Received 2 June 2010; revised 14 July 2010; accepted 30 July 2010; published online 30 September 2010 
$\mathrm{BP}$ and heart rate were measured three times, at 2 min intervals, on the nondominant arm using a validated automatic oscillometric device (Omron Matsusaka, Kioto, Japan).

\section{Augmentation index (AIx) and 'central' BP parameters}

The central hemodynamic measurements employed in this study have been previously validated. ${ }^{10}$ Radial artery waveforms were obtained with a high-fidelity micromanometer (SPC-301; Millar Instruments, Houston, TX, USA) from the wrist and a corresponding central waveform was generated with a validated transfer function (Sphygmocor, AtCor Medical, Sydney, Australia), as previously described in detail and validated. ${ }^{10,11}$ Calibration of the radial arterial waveform obtained by applanation tonometry was carried out with systolic blood pressure and DBP values recorded non-invasively on the contralateral side using a validated automatic oscillometric device (Omron Matsusaka). DBP and mean arterial pressures were assumed to remain constant throughout the arterial tree.

The augmentation pressure (AP) was the height of the late systolic peak above the inflection. The aortic or central AIx was calculated as the ratio of the pressure difference between the 'shoulder' of the pressure wave and the 'peak' systolic pressure $(\Delta P)^{12}$ and the pulse pressure (PP) according to the following formula: $\mathrm{AIx}=(\Delta P / \mathrm{PP}) \times 100$. Values were considered positive if the 'shoulder' occurred before the peak pressure and negative if the shoulder occurred after the pressure peak.

The central pulse pressure $(\mathrm{cPP})$ was calculated as the difference between the estimated aortic systolic and diastolic pressures. ${ }^{11}$

\section{Arterial stiffness and wave reflection measurements}

The arterial stiffness and wave reflection measurements were obtained following current guidelines. ${ }^{10} \mathrm{BP}$ and heart rate were measured three times, at $2 \mathrm{~min}$ intervals, on the non-dominant arm, using a validated automatic oscillometric device (Omron Matsusaka). The mean value from these three measurements was used for further analysis. The pulse wave velocity (PWV), a classic index of arterial stiffness, was measured along the descending thoraco-abdominal aorta by the foot-to-foot velocity method, as previously published and validated. ${ }^{13}$ Briefly, waveforms were obtained transcutaneously over the common carotid artery and the right femoral artery, and the time delay $(t)$ was measured between the feet of the two waveforms. The distance $(D)$ covered by the waves was assimilated to the distance measured between the two recording sites. The $\mathrm{PWV}$ was calculated as $\mathrm{PWV}=D$ (meters) $/ t$ (seconds) ${ }^{14}$ using the Sphygmocor system (AtCor Medical) on the day of the echocardiography assessment and after an overnight fast.

\section{Echocardiography}

A two-dimensional echocardiogram was performed at rest in the left lateral decubitus position with commercially available ultrasound systems equipped with tissue Doppler imaging software (ATL 5000; Bothell, WA, USA). Multiplefrequency phased array transducers $(2-4 \mathrm{MHz})$ were used.

Technical details have been reported previously. ${ }^{15}$ Briefly, the left ventricular mass (LVM) was estimated from the end-diastolic left ventricular internal diameter (LVIDd), interventricular septum and inferolateral wall thickness (ILW) by Devereux's formula ${ }^{16}$ and was normalized to the body surface area (BSA) and height. ${ }^{2.7}$

The BSA was calculated using the Dubois and Dubois formula:

$$
\mathrm{BSA}=0.20247\left[\text { weight }^{0.425} \times(\text { height } / 100)^{0.725}\right] \text {. }
$$

The relative wall thickness was calculated as $(2 \times$ ILW $) /$ LVIDd. Patterns of left ventricular geometry were defined according to European Society of Hypertension/European Society of Cardiology ${ }^{9}$ recommendations. The left ventricular systolic function was assessed by endocardial fractional shortening ((LVIDd-LVIDs)/LVIDd).

\section{Aortic dimensions}

Aortic size was measured using two-dimensional echocardiography; images of the proximal aortic root were obtained from a parasternal long axis view, as the maximal distance between the two leading edges of the anterior and posterior aortic root walls at the end diastole. ${ }^{17}$ Consistently, the proximal aorta was measured at the following sites: the sinus of Valsalva, usually called the aortic root diameter, the sino-tubular junction and the ascending aorta $1 \mathrm{~cm}$ immediately above the sino-tubular junction. All aortic sizes were normalized to the BSA, as described above. For each patient, the maximal point of aortic diameter normalized for BSA was considered the aortic size index (ASi).

Considering the current literature, the absolute aneurysm size is predictive of negative events such as rupture, death or dissection, but the relative aortic size better predicts the occurrence of rupture and death before operative repair. ${ }^{1}$

\section{Statistical analysis}

The statistical analysis was conducted using SAS V8 software (SAS Institute Cary, NC, USA). The parametric distribution of the variables was analyzed using the Kolmogorov Smirnov test and a residual analysis. The data are expressed as the mean \pm s.d. or as the median and 25th-75th percentile difference if appropriate. Differences between means were examined using a $t$ test or ANOVA for normally distributed variables. Kruskal-Wallis or nonparametric ANOVA were used for non-normally distributed variables.

Multiple regression analyses were used to assess the independent determinants of ASi. Independent variables were selected based on their known or expected association with ASi.

Statistical significance was assumed if the null hypothesis could be rejected at $P<0.05$.

\section{RESULTS}

Baseline characteristics of the 190 study participants are shown in Table 1 . None of the subjects had a dilatation involving only the sinotubular junction; dilatation involved the sinus of Valsalva in most patients (132 pts; 68\%) and the ascending aorta in $32 \%$ of the patients. Clinical and echocardiographic parameters were similar in the two subgroups (Table 2). Furthermore, the central pressure and arterial stiffness parameters (that is, AIx and PWV) were not significantly different in patients with sinus of Valsalva and ascending aorta dilatation. For this reason, we considered the patients all together in the subsequent analysis.

\section{Table 1 Clinical data of the population}

\begin{tabular}{|c|c|}
\hline Variable & Mean \pm s.d. \\
\hline$n$ & 190 \\
\hline Gender (M/F) & $159 / 31(84 \% / 16 \%)$ \\
\hline Age (years) & $55.51 \pm 11.35$ \\
\hline Hypertension duration (months) & $96(26-156)$ \\
\hline Abdominal circumference $(\mathrm{cm})$ & $99.7 \pm 11.3$ \\
\hline $\mathrm{bSBP} / \mathrm{bDBP}(\mathrm{mm} \mathrm{Hg})$ & $137.54 \pm 13.91 / 82.62 \pm 9.49$ \\
\hline $\mathrm{bPP}(\mathrm{mm} \mathrm{Hg})$ & $54.93 \pm 11.18$ \\
\hline HR (bpm) & $70.04 \pm 10.48$ \\
\hline $\mathrm{BMI}\left(\mathrm{Kg} \mathrm{m}^{-2}\right)$ & $26.82 \pm 3.59$ \\
\hline cSBP $(\mathrm{mm} \mathrm{Hg}) / \mathrm{cDBP}(\mathrm{mm} \mathrm{Hg})$ & $125.74 \pm 12.99 / 83.84 \pm 8.82$ \\
\hline $\mathrm{cPP}(\mathrm{mm} \mathrm{Hg})$ & $41.90 \pm 9.53$ \\
\hline $\mathrm{PWV}\left(\mathrm{ms}^{-1}\right)$ & $7.53 \pm 1.84$ \\
\hline Alx $(\%)$ & $24.49 \pm 10.64$ \\
\hline $\mathrm{AP}(\mathrm{mm} \mathrm{Hg})$ & $10.70 \pm 6.00$ \\
\hline $\mathrm{AP} \times \mathrm{HR}$ & $8.70 \pm 4.99$ \\
\hline Aortic diameter (SOV) (mm) & $38 \pm 5$ \\
\hline Sino-tubular junction (mm) & $32.3 \pm 4.6$ \\
\hline Ascending aorta (mm) & $37.2 \pm 4.9$ \\
\hline Aortic size index $\left(\mathrm{cm} \mathrm{m}^{-2}\right)$ & $2 \pm 0.24$ \\
\hline LVMi $\left(\mathrm{g} \mathrm{m}^{-2}\right)$ & $102.04 \pm 27.55$ \\
\hline
\end{tabular}

Abbreviations: Alx, Augmentation index; $\mathrm{AP} \times \mathrm{HR}$, AP corrected for heart rate; AP, augmentation pressure; BMI, body mass index; CDBP, central DBP; cSBP, central SBP; DBP, diastolic blood pressure; HR, heart rate; LVMi, left ventricular mass index; PWV, pulse wave velocity; SBP, systolic blood pressure; SOV, sinus of Valsalva. 
Table 2 Clinical and hemodynamic parameters in patients with enlarged sinus of Valsalva or ascending aorta

\begin{tabular}{|c|c|c|c|}
\hline & Sinus of Valsalva & Ascending aorta & \\
\hline Gender (M/F) & $52 / 8$ & $23 / 4$ & 0.85 \\
\hline Hypertensive duration (months) & $126(48-192)$ & $120(36-156)$ & 0.6 \\
\hline Abdominal circumference $(\mathrm{cm})$ & $99.1 \pm 9.46$ & $101.46 \pm 10.45$ & 0.62 \\
\hline $\mathrm{bSBP} / \mathrm{bDBP}(\mathrm{mm} \mathrm{Hg})$ & $137.5 \pm 12.56 / 81.7 \pm 9.90$ & $140.59 \pm 16.02 / 81.70 \pm 8.67$ & $0.12 / 0.46$ \\
\hline $\mathrm{BMI}\left(\mathrm{Kg} \mathrm{m}^{-2}\right)$ & $26.1 \pm 2.55$ & $27.48 \pm 3.00$ & 0.02 \\
\hline cSBP/cDBP $(m m ~ H g)$ & $126.9 \pm 12.5 / 83.32 \pm 8.79$ & $129.6 \pm 14.9 / 83.0 \pm 7.9$ & $0.38 / 0.87$ \\
\hline $\mathrm{cPP}(\mathrm{mm} \mathrm{Hg})$ & $43.6 \pm 9.3$ & $46.6 \pm 12.0$ & 0.21 \\
\hline Alx $(\%)$ & $28.42 \pm 11.51$ & $28.6 \pm 7.3$ & 0.95 \\
\hline $\mathrm{PWV}\left(\mathrm{ms}^{-1}\right)$ & $7.56 \pm 1.96$ & $8.24 \pm 2.53$ & 0.27 \\
\hline LVMi $\left(\mathrm{g} \mathrm{m}^{-2}\right)$ & $108.5 \pm 33.44$ & $108.28 \pm 31.79$ & 0.97 \\
\hline Asc $(\mathrm{cm})$ & $3.83 \pm 0.3$ & $4.26 \pm 0.37$ & $<0.0001$ \\
\hline ASi $\left(\mathrm{cm} \mathrm{m}^{-2}\right)$ & $2.21 \pm 0.16$ & $2.21 \pm 0.15$ & 0.87 \\
\hline
\end{tabular}

Abbreviations: Alx, Augmentation index; Asc, ascending aorta; ASi, aortic size index; bDBP, brachial diastolic blood pressure; BMI, body mass index; bPP, brachial pulse blood pressure; bSBP, brachial systolic blood pressure; cSBP, central systolic blood pressure; HR, heart rate; LVMI, left ventricular mass index; PWV, pulse wave velocity; RWT, relative wall thickness; SOV, Sinus of Valsalva; SOVind, sinus of Valsalva indexed for body surface area; STj, Sino-tubular junction.

First, we analyzed which anthropometric variables were associated with aortic size. The dilatation of the proximal aorta was associated with age $(r=0.37 ; P<0.0001)$, duration of hypertension $(r=0.20 ; P=0.01)$ and heart rate $(r=-0.21 ; P=0.002)$. The correlation with the duration of hypertension was not significantly influenced by age and the association between aortic size and heart rate was no longer significant after the correction for age. The aortic diameter was not significantly associated with bBP (for example, brachial SBP: $r=0.05, P=0.47$ ).

The maximum diameter of the proximal aorta correlated with the body size parameters, such as body weight $(r=0.46 ; P<0.0001)$, height $(r=0.35 ; \quad P<0.0001)$, abdominal circumference $(r=0.47$; $P<0.0001)$ and BMI $(r=0.33 ; P<0.0001)$.

When we examined the central hemodynamic variables, we found that the proximal aortic diameter did not correlate with the central systolic blood pressure, DBP, MBP or PP ( $P>0.05$, data not shown). The absolute value of the aortic size was not associated with the AIx $(r=-0.05 ; P=0.46)$ and PWV $(r=0.11 ; P=0.18)$.

To minimize the impact of body size on the aortic dimensions, the maximum diameter of the proximal aorta was indexed for BSA (ASi).

Considering the clinical variables, ASi was related to bPP $(r=0.19$; $P=0.008$ ), but was not related to systolic or diastolic brachial blood pressure (brachial SBP, brachial DBP; $P>0.05$ ). Furthermore, ASi was inversely related to heart rate $(r=-0.25 ; P=0.0005)$.

ASi was significantly associated with age $(r=0.45 ; P<0.0001)$, but not with BMI $(r=-0.09 ; P=0.17)$ or abdominal circumference $(r=-0.11 ; P=0.27)$.

We found a significant association between cPP $(r=0.28$; $P<0.0001$ ) and ASi (Figure 1a), whereas the central systolic, diastolic and mean BP were not related to ASi.

Considering parameters describing arterial stiffness, we observed a significant association between AP $(r=0.36 ; P<0.0001)$, AIx (Figure $1 \mathrm{~b}$; $r=0.30 ; P<0.0001)$ and ASi, even after correction for age.

Notably, PWV was not related to aortic dimension $(P=$ not significant for both the absolute and the indexed value).
A value $\geqslant 2 \mathrm{~cm} \mathrm{~m}^{-2}$ in the ASi was considered the cutoff value to define aortic dilatation. Table 3 summarizes demographic and clinical characteristics of hypertensive patients grouped into normal $v s$. enlarged ASi.

Hypertensive patients with enlarged ASi were significantly older, had a longer history of hypertension and slightly lower BMI than patients with normal ASi. Brachial SBP and brachial DBP were similar, whereas PP was significantly higher in patients with increased ASi. Analyzing the central hemodynamic, hypertensive patients with ASi dilatation had a significantly higher central systolic and PP. We further found a significantly higher AP and AIx in patients with increased ASi.

Interestingly, the association explored by the linear regression analysis between ASi with $\mathrm{AIx}(P=0.009), \mathrm{cPP}(P=0.007)$ and AP $(P=0.01)$ was significant in the subgroup of patients with enlarged $\mathrm{ASi}$, whereas statistical significance was lost in patients with normal ASi $\left(<2 \mathrm{~cm} \mathrm{~m}^{-2}\right)$.

Last, to evaluate differences in the hemodynamic variables that may be influenced by ASi, we analyzed bBP and cBP levels in relation to the proximal aorta absolute diameter in the two groups of patients identified by normal or enlarged ASi values.

Patients with normal ASi demonstrated a significant inverse correlation between $\mathrm{CPP}$ and the proximal aortic diameter $(r=-0.2$; $P<0.05)$, whereas this correlation disappeared when we considered subjects with enlarged ASi (Figure 2).

Considering the association between AIx and the absolute value of the proximal aortic diameter, we observed (Figure 3) a significant inverse correlation for both groups of patients having an enlarged and normal aortic size, but the linear association was steeper $(\beta 0.11$ and $\beta 0.17, P<0.05$ for both) in subjects with normal ASi.

Of note, both associations with $\mathrm{CPP}$ and AIx $v$ s. the proximal aortic diameter were not significant in the first set of analyses, in which patients were considered as a sole group, irrespective of their ASi. This finding supports the hypothesis of a different hemodynamic pattern in the two groups. 

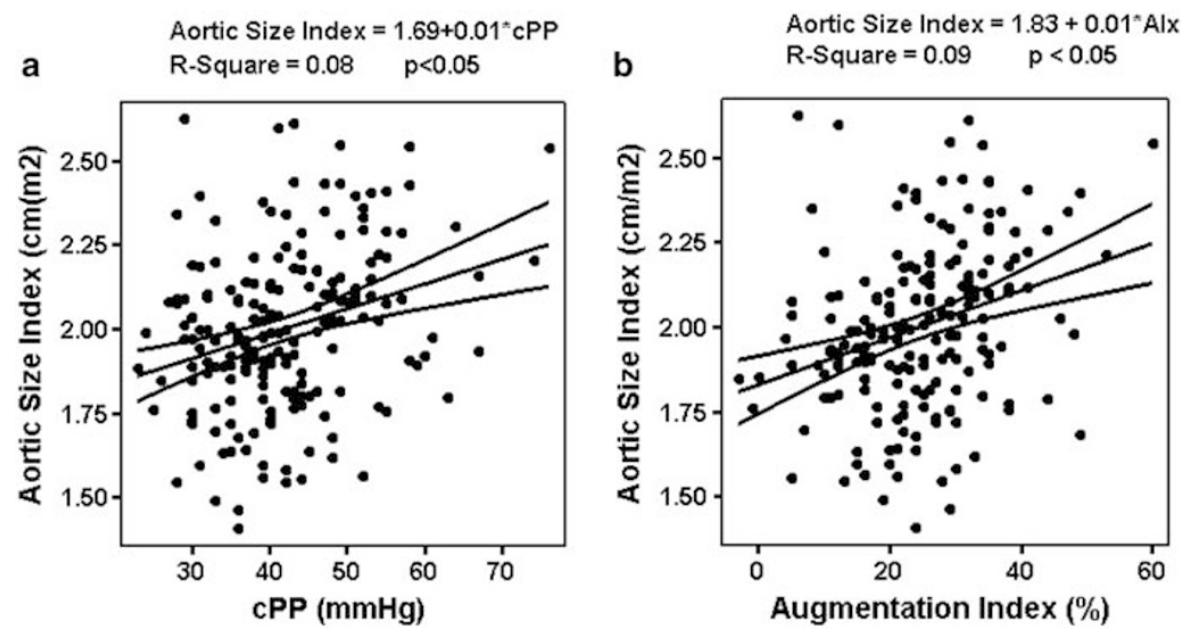

Figure 1 (a) Association between central the pulse pressure (cPP) and aortic size index (ASi). (b) Association between augmentation index (Alx) and ASi.

Table 3 Clinical and hemodynamic parameters in patients with normal and enlarged aortic diameter

\begin{tabular}{|c|c|c|c|}
\hline Variable & $\begin{array}{l}\text { Aortic size index } \\
\quad<2 \mathrm{~cm} \mathrm{~m}^{-2}\end{array}$ & $\begin{array}{c}\text { Aortic size } \\
\text { index } \geqslant 2 \mathrm{~cm} \mathrm{~m}^{-2}\end{array}$ & $P$ \\
\hline$n$ & 102 & 88 & \\
\hline Gender (M/F) & $83 / 19$ & $76 / 12$ & 0.46 \\
\hline Age (years) & $51.27 \pm 10.88$ & $60.47 \pm 9.82$ & $<0.0001$ \\
\hline $\begin{array}{l}\text { Duration of hypertension } \\
\text { (months) }\end{array}$ & $72(24-120)$ & $120(48-180)$ & 0.02 \\
\hline Abdominal circumference $(\mathrm{cm})$ & $99.75 \pm 12.89$ & $99.72 \pm 9.59$ & 0.98 \\
\hline BMI $\left(\mathrm{Kg} \mathrm{m}^{-2}\right)$ & $27.01 \pm 4.13$ & $26.59 \pm 2.83$ & 0.02 \\
\hline $\mathrm{bSBP}(\mathrm{mm} \mathrm{Hg})$ & $136.63 \pm 14.10$ & $138.60 \pm 13.68$ & 0.86 \\
\hline bDBP (mm Hg) & $83.32 \pm 9.51$ & $81.80 \pm 9.47$ & 0.82 \\
\hline bMBP (mm Hg) & $101.09 \pm 10.16$ & $100.73 \pm 9.51$ & 0.87 \\
\hline bPP (mm Hg) & $53.30 \pm 10.26$ & $56.81 \pm 11.94$ & 0.02 \\
\hline $\mathrm{HR}(\mathrm{bpm})$ & $72.24 \pm 10.25$ & $67.49 \pm 10.22$ & 0.001 \\
\hline $\mathrm{cSBP}(\mathrm{mm} \mathrm{Hg})$ & $123.84 \pm 12.55$ & $127.91 \pm 13.22$ & 0.03 \\
\hline cDBP $(\mathrm{mm} \mathrm{Hg})$ & $84.30 \pm 9.11$ & $83.31 \pm 8.49$ & 0.44 \\
\hline cMBP $(\mathrm{mm} \mathrm{Hg})$ & $101.70 \pm 9.89$ & $101.77 \pm 9.72$ & 0.96 \\
\hline cPP $(\mathrm{mm} \mathrm{Hg})$ & $39.54 \pm 8.27$ & $44.60 \pm 10.18$ & $<0.0001$ \\
\hline $\mathrm{PWV}\left(\mathrm{ms}^{-1}\right)$ & $7.36 \pm 1.59$ & $7.75 \pm 2.11$ & 0.22 \\
\hline $\mathrm{Ai}(\%)$ & $21.16 \pm 9.75$ & $28.32 \pm 10.38$ & $<0.0001$ \\
\hline Ai (HR75) & $18.91 \pm 10.15$ & $23.72 \pm 9.75$ & 0.001 \\
\hline $\mathrm{AP}(\mathrm{mm} \mathrm{Hg})$ & $8.65 \pm 4.93$ & $13.06 \pm 6.27$ & $<0.0001$ \\
\hline $\mathrm{AP} \times \mathrm{HR}(\mathrm{mm} \mathrm{Hg})$ & $7.49 \pm 4.69$ & $10.10 \pm 4.99$ & $<0.0001$ \\
\hline $\begin{array}{l}\text { Treated (number of } \\
\text { treated vs. not treated) }\end{array}$ & $75 \%(76 / 26)$ & $100 \%(88 / 0)$ & $<0.0001$ \\
\hline ACE-I (\%) & $16 \%(16 / 86)$ & $23 \%(20 / 68)$ & 0.23 \\
\hline ARB (\%) & $48 \%(49 / 53)$ & $61 \%(54 / 34)$ & 0.06 \\
\hline$\beta$-blockers (\%) & $16 \%(16 / 86)$ & $33 \%(29 / 59)$ & 0.003 \\
\hline CCB (\%) & $34 \%(35 / 67)$ & $57 \%(50 / 38)$ & 0.002 \\
\hline MR antagonists (\%) & $4 \%(4 / 98)$ & $7 \%(6 / 82)$ & 0.38 \\
\hline Thiazides (\%) & $20 \%(21 / 82)$ & $35 \%(31 / 57)$ & 0.01 \\
\hline Number of drugs & $1(0-2)$ & $2(1-3)$ & $<0.0001$ \\
\hline
\end{tabular}

Abbreviations: ACE-I, Aangiotensin-converting enzyme inhibitors; Alx (HR75A), Alx corrected for heart rate; Alx, Augmentation index; AP $\times \mathrm{HR}, \mathrm{AP}$ corrected for heart rate; AP, augmentation pressure; ARB, Angiotensin II receptor blockers; $\mathrm{bDBP}$, brachial diastolic blood pressure; bMBP, brachial mean blood pressure; BMI, body mass index; bPP, brachial mean blood pressure; bSBP, brachial systolic blood pressure; CCB, Calcium channel blockers; CDBP, central diastolic blood pressure; cMBP, central mean blood pressure; cPP, central Pulse Pressure; cSBP, central systolic blood pressure; HR, heart rate; MR, mineralcorticoid receptor; cSBP, central systolic blood
PWV, pulse wave velocity.

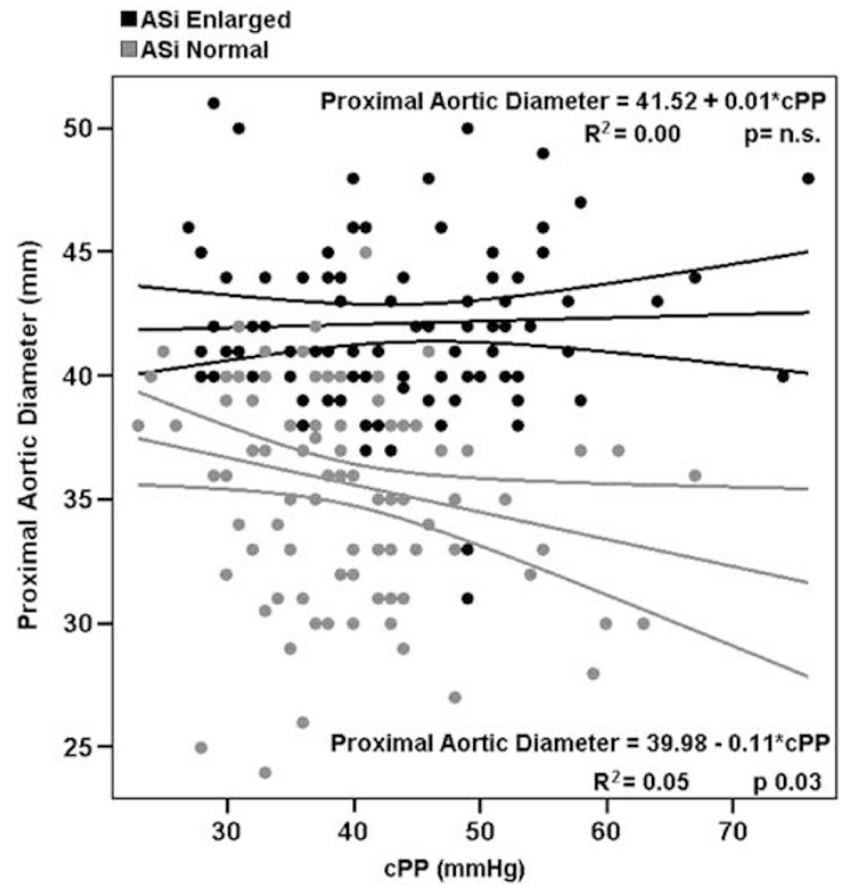

Figure 2 Linear regression between the proximal aortic diameter and the cPP.

We further analyzed the cardiac organ damage associated with ASi enlargement (Table 4).

ASi was significantly related to left ventricular mass (indexed for BSA: $r=0.25, P=0.0004$; indexed for height ${ }^{2.7}: r=0.25, P=0.0004$ ), but no association was observed with relative wall thickness.

Patients with increased ASi demonstrated a higher prevalence of left ventricular hypertrophy (37\%) compared with patients with normal aortic dimensions $(25 \%, P=0.03)$.

Finally, the aortic dimension was significantly associated with the left atrial volume $(r=0.29 ; P<0.0001)$.

Patients with higher ASi were treated with a significantly higher number of drugs (Table 3 ). In particular, a significantly higher 


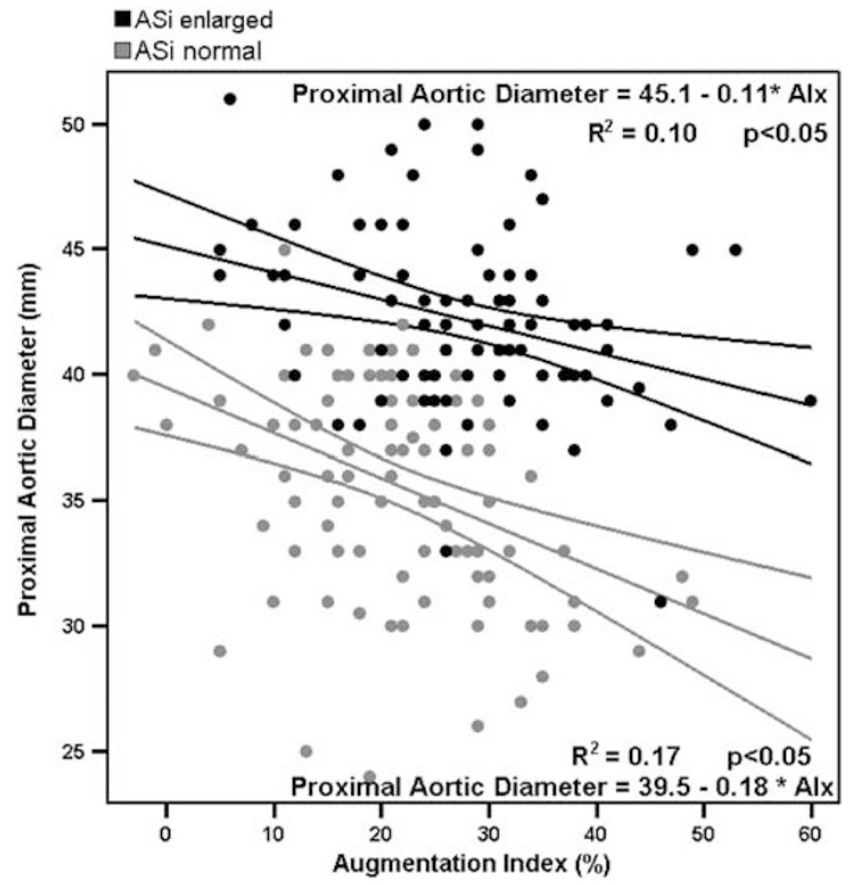

Figure 3 Linear regression between the proximal aortic diameter and the Alx.

Table 4 Echocardiographic parameters in patients with normal and enlarged aortic diameter

\begin{tabular}{|c|c|c|c|}
\hline Variable & $\begin{array}{l}\text { Aortic size index } \\
\quad<2 \mathrm{~cm} \mathrm{~m}^{-2}\end{array}$ & $\begin{array}{c}\text { Aortic size index } \\
\geqslant 2 \mathrm{~cm} \mathrm{~m}^{-2}\end{array}$ & $P$ \\
\hline$n$ & 102 & 88 & \\
\hline \multicolumn{4}{|l|}{ Cardiac morphology } \\
\hline LAD (mm) & $37.57 \pm 5.61$ & $38.53 \pm 5.88$ & 0.29 \\
\hline LAVi $\left(\mathrm{cc} \mathrm{m}^{-2}\right)$ & $27.05 \pm 7.20$ & $31.67 \pm 10.58$ & 0.003 \\
\hline LVMi $\left(\mathrm{g} \mathrm{m}^{-2}\right)$ & $98.45 \pm 25.26$ & $108.57 \pm 32.58$ & 0.02 \\
\hline LVMheight $\left(\mathrm{g} \mathrm{m}^{-1} 2.7\right.$ ) & $43.50 \pm 12.18$ & $48.41 \pm 15.72$ & 0.03 \\
\hline RWT & $0.40 \pm 0.08$ & $0.41 \pm 0.08$ & 0.43 \\
\hline EF (\%) & $62.81 \pm 13.97$ & $62.09 \pm 18.95$ & 0.99 \\
\hline \multicolumn{4}{|l|}{ Transmitral flow } \\
\hline$E\left(m s^{-1}\right)$ & $0.63 \pm 0.16$ & $0.59 \pm 0.11$ & 0.01 \\
\hline$A\left(m^{-1}\right)$ & $0.64 \pm 0.16$ & $0.70 \pm 0.16$ & 0.01 \\
\hline$E / A$ & $1.03 \pm 0.31$ & $0.89 \pm 0.34$ & 0.003 \\
\hline Deceleration time $(\mathrm{m} \mathrm{s})$ & $182.51 \pm 49.20$ & $195.65 \pm 57.65$ & 0.11 \\
\hline
\end{tabular}

Abbreviations: $A$, transmitral atrial wave; $E$, transmitral early wave; $E / A$, transmitral $E$ to $A$ ratio; $E F$, Ejection fraction; LAD, left atrial dimension; LAVi, Left atrial volume index; LVMheight, left ventricular mass indexed for height ${ }^{2.7}$; LVMi, left ventricular mass index; RWT, relative wall thickness; RWT, relative wall thickness.

percentage of these patients were under treatment with calcium channel blockers, $\beta$ blockers and thiazides compared with patients with normal ASi.

To investigate the interactions among the different variables with a potential effect on $\mathrm{ASi}$, we performed a multiple regression analysis (Table 5). Age and AP were significant, independent predictors of increased ASi.
Table 5 Multiple regression analysis

\begin{tabular}{lccc}
\hline Variable & $\beta \pm$ s.e. & $T$ & $P$ \\
\hline Intercept & $1.73 \pm 0.1$ & 10.7 & $<0.0001$ \\
Age (years) & $0.008 \pm 0.001$ & 5.25 & $<0.0001$ \\
Augmentation pressure (mm Hg) & $0.008 \pm 0.004$ & 2.3 & 0.04 \\
CPP (mm Hg) & $-0.001 \pm 0.002$ & -0.57 & 0.56 \\
Heart rate (b.p.m.) & $-0.003 \pm 0.001$ & -1.91 & 0.057 \\
\hline
\end{tabular}

Abbreviation: $\mathrm{CPP}$, central pulse pressure.

\section{DISCUSSION}

The present study has demonstrated for the first time the association between the ASi and central hemodynamic indexes, in particular with cPP and AIx, in a hypertensive population. We observed a significant association between cardiac organ damage and aortic size, confirming previous studies in this field. ${ }^{2}$

Moreover, considering the absolute value of the proximal aorta, we demonstrated, for the first time, a significantly different hemodynamic pattern between subjects with normal vs. enlarged ASi; subjects with increased ASi had higher levels of AIx compared with the control group. This finding is consistent with the hypothesis of a possible loss of the buffering properties of the enlarged aorta at increased levels of cPP in subjects with increased ASi.

The aging process directly affects aortic size in relation to the progressive thinning and fragmentation of elastic fibers. In agreement with previous reports, ${ }^{2,18}$ we confirmed the association between age and aortic dimensions. However, older age cannot completely explain the overall variance of aortic enlargement. Of note, about $20 \%$ of our patients with aortic dilatation were younger than 50 years. It is then reasonable to consider the possible role had by hypertension in ARD. Arterial hypertension is thought to accelerate the age-associated proximal aortic dilatation, ${ }^{19}$ even if previous studies demonstrated a modest association between clinical BP levels and aortic size.,20 We observed that the absolute aortic diameter was not significantly associated with bBP levels, in agreement with previous studies. ${ }^{2,20}$

Different reports ${ }^{2,21,22}$ have demonstrated an association between smaller aortic diameter and increased PP in patients with normal aortic dimensions, suggesting that a smaller aortic root could be responsible for an increased PP and aortic stiffness. We observed an inverse relationship between ASI and AIx with aortic size in the normal range; this supports the hypothesis of small aortic root size pre-disposing patients to a higher CPP and AIx irrespective of PWV (which appeared to be not statistically different). These findings confirm previous reports in this field. ${ }^{18}$

The above mentioned inverse relation between cPP and the absolute aortic dimension in the subgroup of patients having normal ASi could not be demonstrated in subjects with enlarged ASi. This finding is of particular value because such a subgroup of subjects has not been analyzed in previous reports.

The aorta is a dynamic organ that undergoes remodeling in response to hemodynamic demands.

We demonstrated that, in both groups (enlarged and normal ASi), larger proximal aorta diameters corresponded to lower levels of AIx, but considering the same absolute value of the proximal aortic diameter, subjects with enlarged ASi may work at higher levels of AIx compared with the normal ASi group.

These findings suggest an impairment of the aorta buffering elastic properties in subjects with enlarged ASi and are consistent with the hypothesis of the aortic diameter becoming dependent on the 
variation of central hemodynamics (cPP and AIx) once aortic dilatation has occurred.

It has been demonstrated that not only age but also body size account for the aortic root diameter; ${ }^{23}$ to reduce the confounding effect of body size, we normalized the aortic dimension to the BSA.

Of note, Pape et al. ${ }^{24}$ demonstrated that absolute aortic size alone is not a good predictor of aortic dissection type A; the majority of patients with acute type A aortic dissection had an aortic diameter less than $5.5 \mathrm{~cm}$, a measure that is considered the cutoff value for suggesting aortic replacement by current guidelines. Even more strict criteria $(<5 \mathrm{~cm})$ would fail to prevent $40 \%$ of the acute aortic dissections. Thus, the absolute aortic diameter is not a good enough marker of risk for aortic dissection.

Davies et al. demonstrated that ASi is the strongest predictor of aortic rupture and death before operative repair. ${ }^{1}$ Thus, we investigated the association between the ASi and different clinical, hemodynamic and cardiac variables.

We observed an inverse relationship between heart rate and $\mathrm{ASi}$, in agreement with a recent paper by Williams et al. ${ }^{3}$ that demonstrated a clear inverse association between heart rate and cPP and AIx. This association was explained by an increased reflective component of the aortic waveform. These findings considered together with our results may suggest a potential role of low heart rate in aortic dilatation. An increased reflective component due to low heart rate may increase the AIx, resulting in an increased stress on the aortic root

We found that aortic size, normalized for BSA, was positively and significantly associated with central hemodynamic variables. In particular, ASi was significantly associated with cPP, AP and AIx, before and after the correction for age.

Interestingly, the positive associations between $\mathrm{ASi}$ and $\mathrm{AIx}$, as well as between $\mathrm{CPP}$ and $\mathrm{AP}$ were significant in the subgroup of patients with enlarged $\mathrm{ASi}$, whereas statistic significance was lost in patients with normal ASi (less than $2 \mathrm{~cm} \mathrm{~m}^{-2}$ ).

Marfan's syndrome can be considered a prototypical extreme of great arterial medial wall abnormalities. Previous studies have shown that aortic dilation in patients affected by Marfan's syndrome was related to $\mathrm{cPP}$, but not $\mathrm{bPP}^{8}$

In hypertensive subjects, collagen and elastin abnormalities are usually more pronounced than in age matched normotensive subjects, ${ }^{25}$ but this process is magnified in Marfan's syndrome.

Based on our findings, hypertensive patients with enlarged ASi should be considered an intermediate phenotype between Marfan and normal aorta; in fact, they lose part but not all of the elastic properties of the aorta, demonstrating a more strict correlation with central hemodynamics than subjects with normal ASi. These findings may suggest that the inverse relationship between aortic diameter and central hemodynamics (cPP, AIx and AP) usually present in the normal range of aortic dimensions is attenuated in hypertensives with a larger aortic root. A larger aortic root could represent a type of maladaptation of the aorta to the wall stress, pre-disposing it to further dilatation.

In our study, we demonstrated a significant association between ASi and cardiac organ damage. In particular, patients with enlarged ASi had an increased prevalence of left ventricular hypertrophy and a more pronounced left atrial volume, than those with normal ASi, confirming previous studies in this field. ${ }^{2}$ These findings support the association between cardiac organ damage and aortic size.

Current guidelines do not provide suggestions for the preferred therapy for hypertensive patients with aortic dilatation. Marfan's syndrome is a genetic condition associated with aortic dilatation. In studies performed in a relatively small population, it has been reported that $\beta$-blockers delay ARD in patients with this disease. A recent meta-analysis ${ }^{26}$ failed to provide significant evidence that therapy with $\beta$-blockers affects long-term outcome. In a mouse model of aortic dilation, treatment with losartan proved to be more effective than propranolol in reducing and reverting aortic wall disarray. ${ }^{27}$ In agreement with this finding, two clinical trials recently demonstrated that the inhibition of the renin-angiotensin-aldosterone system by angiotensin-converting enzyme inhibitors ${ }^{28}$ or angiotensin receptor blockers ${ }^{29}$ reduced the rate of aortic enlargement in patients affected by Marfan's syndrome.

Considering $\beta$-blocker therapy, we observed an increased percentage of treatment in patients affected by aortic root enlargement. Furthermore, $\beta$-blocker therapy was associated with a higher AIx, as previously observed in the CAFÉ trial. ${ }^{30}$

\section{LIMITATIONS OF THE STUDY}

This is a cross-sectional study evaluating a relatively young population (mean age, 55 years old); a significant percentage of our patients had a mild proximal aortic dilatation. Longitudinal studies will be required to describe the natural history of proximal aortic dilatation and to determine whether younger individuals with increased AIx or cPP are more likely to develop aortic dilatation and whether adult or older subjects with increased levels of central hemodynamic (AIx or cPP) have a higher risk of aortic dissection.

Almost all of the patients were under pharmacological treatment with different classes of drugs. This treatment can potentially affect several of the examined variables, particularly central hemodynamics and PWV. In fact, all PWV values were within the normal range, and the lack of association between PWV and aortic diameter can probably be explained by the effect of the antihypertensive treatment. Fifty percent of the patients enrolled in the study had an increase in aortic dimensions and thus, for ethical reasons, we could not perform a period of wash out in our patients. Further studies may be addressed to evaluate the potential effect of drug therapy on aortic dimensions and central hemodynamics.

Finally, in our paper we did not evaluate the aortic wall thickness, which is related to wall stress. Wall stress increases in correlation with the increased aortic radius and it is inversely related to the aortic wall thickness according to La Place's law. In this view, a more accurate evaluation of the aortic wall thickness could improve our understanding of the physiopathological interactions between BP and aortic enlargement. At the same time, it must be kept in mind that assessments of wall thickness are often difficult during a standard echocardiographic exam.

\section{CONCLUSIONS}

ARD is a common clinical feature in arterial hypertension. Our study suggests that the most important clinical parameters associated with aortic enlargement are cBP and AIx. Estimation of cPP might then be useful in assessing the effectiveness of treatments to reduce further increases in $\mathrm{ASi}$, given that brachial indexes seem less well related to aortic dimensions. Longitudinal studies will provide more information about the pathophysiological role of the 'central' hemodynamic parameters in aortic root enlargement in hypertensive patients.

\section{CONFLICT OF INTEREST}

The authors declare no conflict of interest. 


\section{ACKNOWLEDGEMENTS}

We thank Dr Eleonora Avenatti, MD, for her contribution to the editing of the paper and the language revision. This study was supported by a grant from the REGIONE PIEMONTE 2007

1 Davies RR, Gallo A, Coady MA, Tellides G, Botta DM, Burke B, Coe MP, Kopf GS, Elefteriades JA. Novel measurement of relative aortic size predicts rupture of thoracic aortic aneurysms. Ann Thorac Surg 2006; 81: 169-177.

2 Cuspidi C, Meani S, Fusi V, Valerio C, Sala C, Zanchetti A. Prevalence and correlates of aortic root dilatation in patients with essential hypertension: relationship with cardiac and extracardiac target organ damage. J Hypertens 2006; 24: 573-580.

3 Williams B, Lacy PS. Impact of heart rate on central aortic pressures and hemodynamics: analysis from the CAFE (Conduit Artery Function Evaluation) Study: CAFE-Heart Rate. J Am Coll Cardiol 2009; 54: 705-713.

4 Roman MJ, Devereux RB, Kizer JR, Okin PM, Lee ET, Wang W, Umans JG, Calhoun D, Howard BV. High Central Pulse Pressure Is Independently Associated With Adverse Cardiovascular Outcome: The Strong Heart Study. J Am Coll Cardiol 2009; 54: 1730-1734.

5 Pini R, Cavallini MC, Palmieri V, Marchionni N, Di Bari M, Devereux RB, Masotti G, Roman MJ. Central but not brachial blood pressure predicts cardiovascular events in an unselected geriatric population: the ICARe Dicomano Study. J Am Coll Cardiol 2008; 51: 2432-2439.

6 Roman MJ, Devereux RB, Kizer JR, Lee ET, Galloway JM, Ali T, Umans JG, Howard BV. Central pressure more strongly relates to vascular disease and outcome than does brachial pressure: the Strong Heart Study. Hypertension 2007; 50: 197-203.

7 Williams B, Lacy PS. Central aortic pressure and clinical outcomes. J Hypertens 2009; 27: 1123-1125.

8 Jondeau G, Boutouyrie P, Lacolley P, Laloux B, Dubourg O, Bourdarias JP, Laurent S. Central pulse pressure is a major determinant of ascending aorta dilation in Marfan syndrome. Circulation 1999; 99: 2677-2681.

9 Mancia G, De Backer G, Dominiczak A, Cifkova R, Fagard R, Germano G, Grassi G, Heagerty AM, Kjeldsen SE, Laurent S, Narkiewicz K, Ruilope L, Rynkiewicz A, Schmieder RE, Boudier HA, Zanchetti A, Vahanian A, Camm J, De Caterina R, Dean V, Dickstein K, Filippatos G, Funck-Brentano C, Hellemans I, Kristensen SD, McGregor K, Sechtem U, Silber S, Tendera M, Widimsky P, Zamorano JL, Erdine S, Kiowski W, Agabiti-Rosei E, Ambrosioni E, Lindholm LH, Viigimaa M, Adamopoulos S, AgabitiRosei E, Ambrosioni E, Bertomeu V, Clement D, Erdine S, Farsang C, Gaita D, Lip G, Mallion JM, Manolis AJ, Nilsson PM, O'Brien E, Ponikowski P, Redon J, Ruschitzka F, Tamargo J, van Zwieten P, Waeber B, Williams B. 2007 Guidelines for the Management of Arterial Hypertension: The Task Force for the Management of Arterial Hypertension of the European Society of Hypertension (ESH) and of the European Society of Cardiology (ESC). J Hypertens 2007; 25: 1105-1187.

10 Agabiti-Rosei E, Mancia G, O'Rourke MF, Roman MJ, Safar ME, Smulyan H, Wang JG, Wilkinson IB, Williams B, Vlachopoulos C. Central blood pressure measurements and antihypertensive therapy: a consensus document. Hypertension 2007; 50: 154-160.

11 Pauca AL, O'Rourke MF, Kon ND. Prospective evaluation of a method for estimating ascending aortic pressure from the radial artery pressure waveform. Hypertension 2001; 38: 932-937.

12 O'Rourke MF, Pauca A, Jiang XJ. Pulse wave analysis. Br J Clin Pharmacol 2001; 51: 507-522.

13 Laurent S, Cockcroft J, Van Bortel L, Boutouyrie P, Giannattasio C, Hayoz D, Pannier B, Vlachopoulos C, Wilkinson I, Struijker-Boudier H. Expert consensus document on arterial stiffness: methodological issues and clinical applications. Eur Heart J 2006; 27: 2588-2605
14 Asmar R, Benetos A, Topouchian J, Laurent P, Pannier B, Brisac AM, Target R, Levy BI. Assessment of arterial distensibility by automatic pulse wave velocity measurement. Validation and clinical application studies. Hypertension 1995; 26: 485-490.

15 Milan A, Caserta MA, Del Colle S, Dematteis A, Morello F, Rabbia F, Mulatero P, Pandian NG, Veglio F. Baroreflex sensitivity correlates with left ventricular morphology and diastolic function in essential hypertension. J Hypertens 2007; 25: 1655-1664.

16 Devereux RB, Reichek N. Echocardiographic determination of left ventricular mass in man. Anatomic validation of the method. Circulation 1977; 55: 613-618.

17 Lang RM, Bierig M, Devereux RB, Flachskampf FA, Foster E, Pellikka PA, Picard MH, Roman MJ, Seward J, Shanewise J, Solomon S, Spencer KT, St John Sutton M, Stewart W. Recommendations for chamber quantification. Eur J Echocardiogr 2006; 7: 79-108.

18 Mitchell GF, Conlin PR, Dunlap ME, Lacourciere Y, Arnold JM, Ogilvie RI, Neutel J, Izzo Jr JL, Pfeffer MA. Aortic diameter, wall stiffness, and wave reflection in systolic hypertension. Hypertension 2008; 51: 105-111.

19 O'Rourke MF, Nichols WW. Aortic diameter, aortic stiffness, and wave reflection increase with age and isolated systolic hypertension. Hypertension 2005; 45: 652-658.

20 Palmieri V, Bella JN, Arnett DK, Roman MJ, Oberman A, Kitzman DW, Hopkins PN, Paranicas M, Rao DC, Devereux RB. Aortic root dilatation at sinuses of valsalva and aortic regurgitation in hypertensive and normotensive subjects: The Hypertension Genetic Epidemiology Network Study. Hypertension 2001; 37: 1229-1235.

21 Bella JN, Wachtell K, Boman K, Palmieri V, Papademetriou V, Gerdts E, Aalto T, Olsen $\mathrm{MH}$, Olofsson M, Dahlof B, Roman MJ, Devereux RB. Relation of left ventricular geometry and function to aortic root dilatation in patients with systemic hypertension and left ventricular hypertrophy (the LIFE study). Am J Cardiol 2002; 89: 337-341.

22 Farasat SM, Morrell CH, Scuteri A, Ting CT, Yin FC, Spurgeon HA, Chen CH, Lakatta EG, Najjar SS. Pulse pressure is inversely related to aortic root diameter implications for the pathogenesis of systolic hypertension. Hypertension 2008; 51: 196-202.

23 Farasat SM, Morrell CH, Scuteri A, Ting CT, Yin CPF, Spurgeon HA, Chen CH, Lakatta GE, Najjar SS. Do hypertensive individuals have enlarged aortic root diameters? Insights from studying the various subtypes of hypertension. Am J Hypertens 2008; 21: 558-563.

24 Pape LA, Tsai TT, Isselbacher EM, Oh JK, O'Gara TP, Evangelista A, Fattori $R$, Meinhardt G, Trimarchi S, Bossone E, Suzuki T, Cooper JV, Froehlich JB, Nienaber $\mathrm{CA}$, Eagle KA. Aortic diameter $>$ or $=5.5 \mathrm{~cm}$ is not a good predictor of type A aortic dissection: observations from the International Registry of Acute Aortic Dissection (IRAD). Circulation 2007; 116: 1120-1127.

25 Carlson RG, Lillehei CW, Edwards JE. Cystic medial necrosis of the ascending aorta in relation to age and hypertension. Am J Cardiol 1970; 25: 411-415.

26 Gersony DR, McClaughlin MA, Jin Z, Gersony WM. The effect of beta-blocker therapy on clinical outcome in patients with Marfan's syndrome: a meta-analysis. Int J Cardiol 2007; 114: 303-308.

27 Habashi JP, Judge DP, Holm TM, Cohn RD, Loeys BL, Cooper TK, Myers L, Klein EC, Liu G, Calvi C, Podowski M, Neptune ER, Halushka MK, Bedja D, Gabrielson K, Rifkin DB, Carta L, Ramirez F, Huso DL, Dietz HC. Losartan, an AT1 antagonist, prevents aortic aneurysm in a mouse model of Marfan syndrome. Science 2006; 312: 117-121.

28 Ahimastos AA, Aggarwal A, D'Orsa KM, Formosa MF, White AJ, Savarirayan R, Dart AM, Kingwell BA. Effect of perindopril on large artery stiffness and aortic root diameter in patients with Marfan syndrome: a randomized controlled trial. Jama 2007; 298: 1539-1547.

29 Brooke BS, Habashi JP, Judge DP, Patel N, Loeys B, Dietz III HC. Angiotensin II blockade and aortic-root dilation in Marfan's syndrome. N Engl J Med 2008; 358: 2787-2795

30 Williams B, Lacy PS, Thom SM, Cruickshank K, Stanton A, Collier D, Hughes AD, Thurston H, O'Rourke M. Differential impact of blood pressure-lowering drugs on central aortic pressure and clinical outcomes: principal results of the Conduit Artery Function Evaluation (CAFE) study. Circulation 2006; 113: 1213-1225. 